\title{
Citrulline cooperatively exerts an anti-inflammatory effect on synovial cells with glucosamine and $\mathbf{N}$-acetylglucosamine
}

\author{
YOSHIE YAMAGISHI, AKIMASA SOMEYA and ISAO NAGAOKA \\ Department of Host Defense and Biochemical Research, Juntendo University, \\ Graduate School of Medicine, Tokyo 113-8421, Japan
}

Received November 27, 2019; Accepted March 12, 2020

DOI: $10.3892 /$ br.2020.1304

\begin{abstract}
The aim of the present study was to evaluate the anti-inflammatory effects of citrulline (Cit), glucosamine (GlcN) and $\mathrm{N}$-acetylglucosamine (GlcNAc) on synovial cells, which are primarily involved in inflammatory joint diseases. The combined effect of Cit, GlcN and GlcNAc on synovial cell inflammation was assessed by measuring IL-1 $\beta$-induced IL-6 production. GlcN and GlcNAc ( $0.5 \mathrm{mM}$ each) alone did not suppress IL-6 production, whereas Cit $(0.5 \mathrm{mM})$ did significantly suppress IL-6 production. Furthermore, the combined effect of Cit, GlcNAc and GlcN was examined; Cit + GlcN and $\mathrm{Cit}+$ GlcNAc significantly suppressed not only IL-6 production, but also phosphorylation of ERK1/2. Similarly, combination of GlcN + GlcNAc significantly suppressed IL-6 production and phosphorylation of ERK1/2. These observations suggest that among Cit, GlcNAc and GlcN, the combination of Cit with GlcN or GlcNAc exerts a synergistic anti-inflammatory effect on synovial cells, thereby possibly exhibiting chondroprotective effects and alleviating inflammatory joint diseases.
\end{abstract}

\section{Introduction}

L-citrulline (Cit) is a free amino acid and functions as an intermediate in the urea cycle. Cit can be readily converted to L-arginine in the kidney, vascular endothelium and other tissues, and is utilized for the production of nitric oxide via L-arginine $(1,2)$. Thus, Cit has been reported to regulate blood pressure via nitric oxide production $(1,2)$. It has been reported that $\mathrm{Cit}$ modulates cytokine production by macrophages (upregulation of IL- 6 and downregulation of TNF- $\alpha$ ) in diabetic and obese individuals (3). In addition, Cit exhibits anti-inflammatory action on ethanol-induced gastric ulcers and non-alcoholic fatty liver disease by reducing pro-inflammatory cytokine (IL-6 and TNF- $\alpha$ ) production $(4,5)$. Recently,

Correspondence to: Professor Isao Nagaoka, Department of Host Defense and Biochemical Research, Juntendo University, Graduate School of Medicine, 2-1-1 Hongo, Bunkyo-ku, Tokyo 113-8421, Japan

E-mail: nagaokai@juntendo.ac.jp

Key words: citrulline, glucosamine, cooperative action, anti-inflammatory action, synovial cell it was reported that administration of Cit and glucosamine $(\mathrm{GlcN})$ in a rat model of osteoarthritis (OA) reduced cartilage damage (6). However, the mechanism underlying their chondroprotective effects have not been elucidated.

As a functional food material, GlcN exhibits a chondroprotective effect on animal models of OA and rheumatoid arthritis by suppressing production of inflammatory cytokines in synoviocytes and chondrocytes (7-10). Furthermore, GlcN improves the symptoms of knee OA in humans; thus, GlcN is widely used for the prevention and treatment of OA (11). $\mathrm{N}$-acetylglucosamine (GlcNAc), a derivative of GlcN, exhibits anti-inflammatory and chondroprotective effects in a rat model of OA by reducing IL-6 production, cyclooxygenase expression and type II collagen degradation (12-15). Furthermore, GlcNAc is reported to improve the symptoms of knee OA in humans $(16,17)$.

Based on these findings, it is hypothesized that Cit, GlcN and GlcNAc may cooperatively act and exhibit improved anti-inflammatory effects in inflammatory joint diseases. However, to the best of our knowledge, the combined effect of Cit, GlcN and GlcNAc on inflammatory joint diseases has not been evaluated. Thus, in the present study, a focus was placed on synovial cells, which are primarily involved in inflammatory joint diseases, and the combined effect of Cit, GlcN and GlcNAc on the synovial cell inflammation was assessed.

\section{Materials and methods}

Cell line and reagents. MH7A human synovial cells were purchased from RIKEN BioResource Center (cat. no. RCB1512). Cit, GlcNAc and GlcN hydrochloride were supplied by Protein Chemical Co., Ltd. IL-1 $\beta$ and FBS were purchased from PeproTech, Inc. and Nichirei Biosciences, Inc., respectively. RPMI-1640 medium, RIPA lysis buffer with protease inhibitor cocktail, Phosphatase Inhibitor Cocktail ${ }^{\mathrm{TM}}$ and Sample Buffer solution with reducing reagent (6x) for SDS-PAGE were obtained from Nacalai Tesque, Inc.

Cell culture. MH7A cells were maintained in RPMI-1640 medium supplemented with 10\% FBS and 100-fold diluted Penicillin-Streptomycin mixed solution (Nacalai Tesque, Inc.), and maintained at $37^{\circ} \mathrm{C}$ with $5 \% \mathrm{CO}_{2}$.

Measurement of $I L-6$. MH7A cells $\left(3 \times 10^{4}\right.$ cells/well) were seeded and cultured in 24-well plates overnight. Cells were 
incubated with Cit $(0.5 \mathrm{mM})$, GlcNAc $(0.5 \mathrm{mM})$ or GlcN (0.5-1.0 mM) alone, or a combination of Cit and GlcN, Cit and GlcNAc, or GlcN and GlcNAc for $2 \mathrm{~h}$ at $37^{\circ} \mathrm{C}$. Subsequently, cells were stimulated with $50 \mathrm{pg} / \mathrm{ml} \mathrm{IL}-1 \beta$ in a total volume of $0.5 \mathrm{ml}$ RPMI-1640 medium for $24 \mathrm{~h}$ at $37^{\circ} \mathrm{C}$. IL-6 in the culture supernatants was quantified using the DuoSet ELISA Development kit (cat. no. DY206-05; R\&D Systems, Inc.). Briefly, a monoclonal antibody specific for IL-6 was precoated onto microtiter plates (96-well half area flat bottom; Corning, Inc.). Standards and samples were pipetted into the wells, and IL-6 was bound to immobilized antibody. After washing with PBS containing $0.05 \%$ Tween-20, an enzyme-linked polyclonal antibody specific for IL-6 was added to the wells. Following washing with PBS containing $0.05 \%$ Tween-20, a substrate solution $(1 \times 3,3$ ',5,5'-Tetramethylbenzidine substrate Solution; cat. no. 00-4201-56; eBioscinece; Thermo Fisher Scientific, Inc.) was added to the wells, and the color was developed. The reaction was stopped by addition of sulfuric acid, and the intensity of developed color was measured using a microplate reader at $450 \mathrm{~nm}$ (Model 680; Bio-Rad Laboratories, Inc.).

Phosphorylation of $p 38$ MAPK, NF- $\kappa B$ and ERK1/2. MH7A cells $\left(3 \times 10^{4} /\right.$ well) were seeded and cultured in 24 -well plates overnight. Cells were incubated with Cit $(0.5 \mathrm{mM})$, GlcNAc $(0.5 \mathrm{mM})$ or GlcN $(0.5 \mathrm{mM})$ alone, or a combination of Cit and GlcN, Cit and GlcNAc, or GlcN and GlcNAc for $2 \mathrm{~h}$, and stimulated with $200 \mathrm{pg} / \mathrm{ml} \mathrm{IL}-1 \beta$ for $30 \mathrm{~min}$ at $37^{\circ} \mathrm{C}$. Following washing with ice-cold PBS, the cells were harvested in $100 \mu \mathrm{l}$ RIPA lysis buffer containing 1/100 v/v Phosphatase Inhibitor Cocktail $^{\mathrm{TM}}$. Following sonication, the lysates were centrifuged at $4^{\circ} \mathrm{C}$ at $12,000 \mathrm{xg}$ for $10 \mathrm{~min}$, and the protein concentrations of the supernatants were determined using a Bicinchoninic Acid protein assay kit (Pierce; Thermo Fisher Scientific, Inc.) using bovine serum albumin as the standard. The supernatants were mixed with 6x SDS-PAGE sample buffer and boiled for $3 \mathrm{~min}$. The mixtures (containing $10 \mu \mathrm{g}$ protein/lane) were separated by $10 \%$ SDS-PAGE and electrophoretically transferred to an Immobilon-P PVDF membrane (EMD Millipore). To detect phosphorylated p38 MAPK, NF-кB and ERK1/2, the membranes were blocked at room temperature for $30 \mathrm{~min}$ in Blocking One solution (Nacalai Tesque, Inc.), and probed with a mouse anti-phospho-(p)-p38 MAPK (pT180/pY182) monoclonal antibody (1:1,000; cat. no. 612168; BD Pharmingen, BD Biosciences), anti-p-NF- $\kappa$ B p65 (Ser536) rabbit monoclonal antibody (1:1,000; cat. no. 3033; Cell Signaling Technology, Inc.) or anti-p-ERK1/2 MAPK (Thr202/Tyr204) rabbit antibody (1:1,000; cat. no. 9101; Cell Signaling Technology, Inc.) at $4^{\circ} \mathrm{C}$ overnight. Horseradish peroxidase (HRP)-conjugated goat anti-mouse immunoglobulin (Ig)G/IgM (1:5,000; cat. no. 115-035-044; Jackson ImmunoResearch Laboratories, Inc.) or HRP-conjugated goat anti-rabbit IgG (1:5,000; cat. no. 12-348; Chemicon International; Thermo Fisher Scientific, Inc.) were used as the secondary antibodies, and incubated with the membranes at room temperature for $1 \mathrm{~h}$.

The membranes were stripped by incubating in Restore Western Stripping Buffer (Pierce; Thermo Fisher Scientific, Inc.) at $37^{\circ} \mathrm{C}$ for $30 \mathrm{~min}$. Total p38 MAPK, NF- $\kappa \mathrm{B}$ and ERK1/2 expression in each sample was detected by reprobing with mouse anti-p38 MAPK antibody (1:2,000; SAPK2a;
A

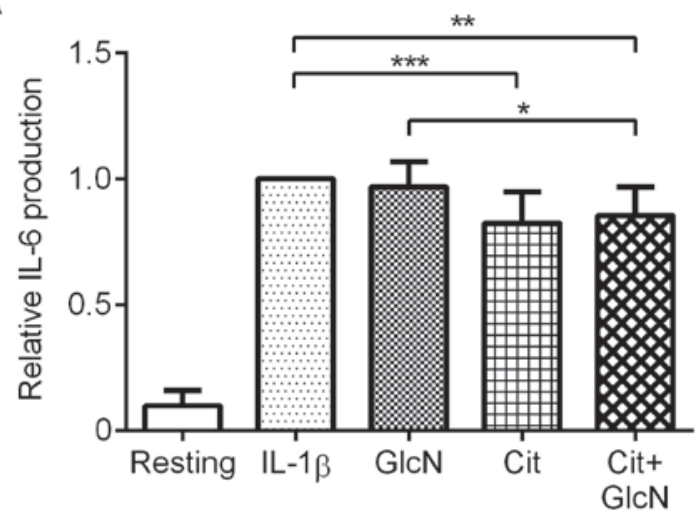

B

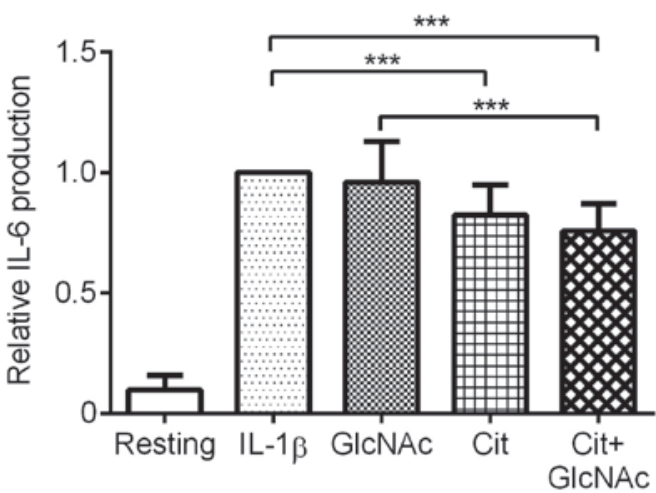

C

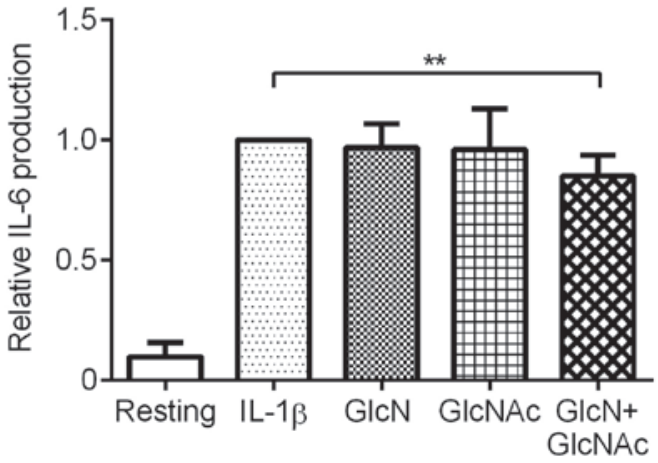

Figure 1. Effect of Cit, GlcNAc or GlcN, and their combinations on IL-1 $\beta$-stimulated IL-6 production by MH7A cells. (A) MH7A cells were incubated with or without IL- $1 \beta$ in the presence of $0.5 \mathrm{mM} \mathrm{GlcN}, 0.5 \mathrm{mM}$ Cit or Cit + GlcN for $24 \mathrm{~h}$. (B) MH7A cells were incubated with or without IL-1 $\beta$ in the presence of $0.5 \mathrm{mM}$ GlcNAc, $0.5 \mathrm{mM}$ Cit or Cit + GlcNAc for $24 \mathrm{~h}$. (C) MH7A cells were incubated with or without IL-1 $\beta$ in the presence of $0.5 \mathrm{mM}$ GlcN, $0.5 \mathrm{mN}$ GlcNAc, or GlcN + GlcNAc for $24 \mathrm{~h}$. IL-6 production was quantified in the supernatant using ELISA. Data are presented as the mean \pm standard deviation of $10-16$ separate experiments. ${ }^{*} \mathrm{P}<0.05,{ }^{* *} \mathrm{P}<0.01$ and ${ }^{* * *} \mathrm{P}<0.001$. Cit, L-citrulline; GlcNAc, N-acetylglucosamine; GlcN, glucosamine.

cat. no. 612168; BD Pharmingen, BD Biosciences), anti-NF-кB p65 rabbit monoclonal antibody $(1: 2,000$; cat. no. 8242; Cell Signaling Technology, Inc.) or anti-ERK1/2 MAPK rabbit antibody (1:2,000; cat. no. 9102; Cell Signaling Technology, Inc.) at $4^{\circ} \mathrm{C}$ overnight, followed by incubating with HRP-conjugated goat anti-mouse $(1: 5,000)$ or anti-rabbit $(1: 5,000) \mathrm{IgG}$ secondary antibody at room temperature for $1 \mathrm{~h}$. GAPDH expression was detected by incubating with a mouse anti-GAPDH monoclonal antibody at $4^{\circ} \mathrm{C}$ overnight (1:50,000; cat. no. MAB374; Chemicon International; Thermo Fisher Scientific, Inc.) and subsequently HRP-conjugated goat 


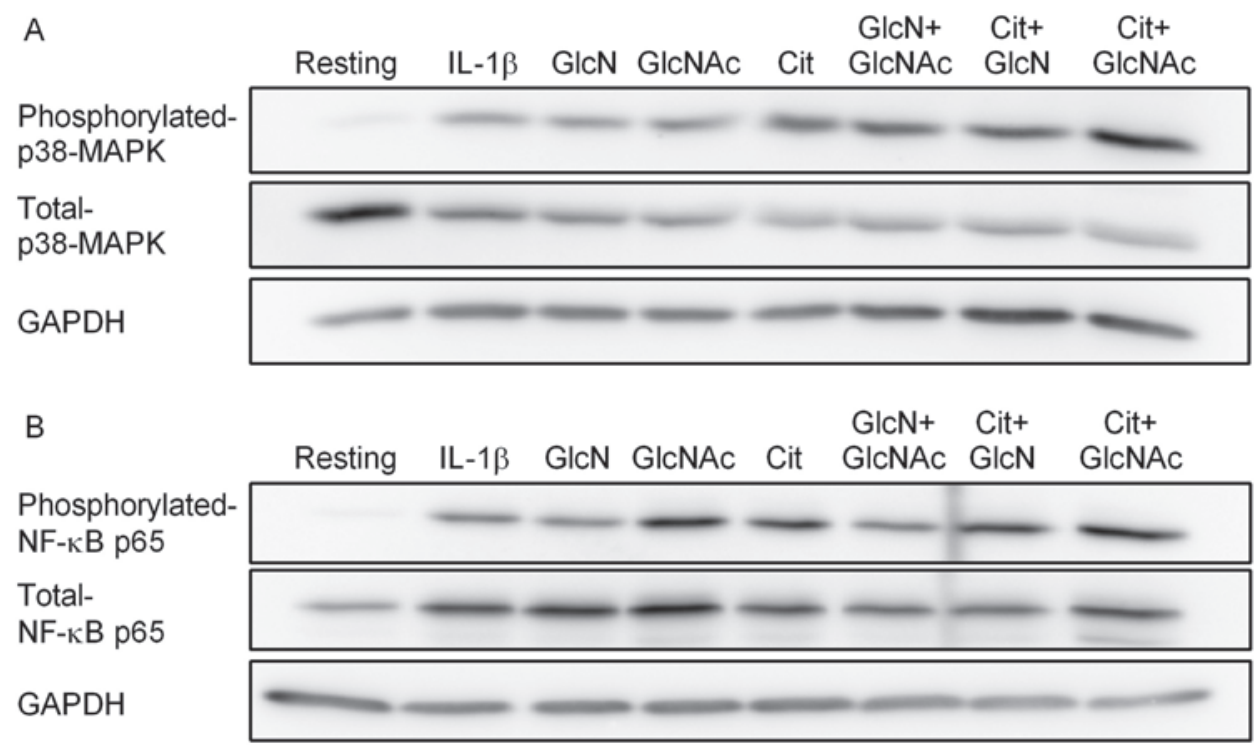

Figure 2. Effect of Cit, GlcNAc or GlcN, and their combinations on IL-1 $\beta$-stimulated phosphorylation of p38 MAPK and NF- $\kappa$ B p65 by MH7A cells. MH7A cells were incubated with or without IL-1 $\beta$ in the presence of $0.5 \mathrm{mM}$ GlcN, $0.5 \mathrm{mM}$ GlcNAc or $0.5 \mathrm{mM}$ Cit alone for $30 \mathrm{~min}$. Alternatively, MH7A cells were incubated with IL-1 $\beta$ in the presence of a combination of GlcN + GlcNAC, Cit + GlcN, or Cit + GlcNAc for 30 min. Western blotting was performed to assess the expression of phosphorylated and total (A) p38 MAPK, and (B) NF- $\mathrm{B}$ p65. GAPDH was used as the loading control. The images are representative of three separate experiments. The vertical lines between GlcN + GlcNAc and Cit + GlcN in the NF- $\kappa \mathrm{B}$ p65 blots are non-specific binding. Cit, L-citrulline; GlcNAc,

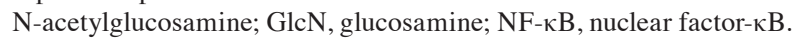

anti-mouse $\operatorname{IgG/IgM}$ at room temperature for $1 \mathrm{~h}(1: 5,000)$. GAPDH was used as the loading control.

Signals were detected using SuperSignal West Dura Chemiluminescent Substrate (Pierce; Thermo Fisher Scientific, Inc.), and quantified using a LAS-3000 luminescent image analyzer and Multi Gauge version 3.0 (both from Fujifilm).

Statistical analysis. Data are expressed as the mean \pm standard deviation, and were analyzed using a one-way ANOVA with a post-hoc Tukey's test using GraphPad Prism version 6 (GraphPad Software, Inc.). $\mathrm{P}<0.05$ was considered to indicate a statistically significant difference.

\section{Results}

Effects of Cit, GlcNAc and GlcN on IL-1 $\beta$-stimulated IL-6 production by $M H 7 A$ cells. GlcN has been reported to significantly reduce the production of inflammatory mediators and inflammatory cytokines such as NO, PGE 2 and IL-8 by synovial cells in vitro at $1 \mathrm{mM}(9)$. Therefore, to evaluate the combined effects of Cit with GlcNAc and GlcN on IL- $1 \beta$-stimulated IL- 6 production by MH7A cells, the concentration of $\mathrm{GlcN}$ was reduced to $0.5 \mathrm{mM}$, a concentration at which GlcN is unlikely to suppress cytokine production. In fact, when MH7A was stimulated with IL-1 $\beta$ in the presence of GlcN (0.5 and $1.0 \mathrm{mM}), 0.5 \mathrm{mM}$ GlcN did not significantly reduce IL-6 production, whereas $1 \mathrm{mM}$ GlcN significantly suppressed production (data not shown). Thus, in the present study, the concentrations of Cit and GlcNAc were adjusted to $0.5 \mathrm{mM}$ (the same concentration as GlcN), and their combined effect was determined. IL-1 $\beta$ stimulation markedly increased the production of IL-6 by MH7A cells (Fig. 1). GlcN alone did not affect IL-1 $\beta$-stimulated IL-6 production by MH7A cells at $0.5 \mathrm{mM}$. However, Cit significantly suppressed IL-6 production $(\mathrm{P}<0.001)$. Combination of $\mathrm{Cit}$ and $\mathrm{GlcN}$ did not further suppress IL- 6 production, although the combination significantly suppressed IL- 6 production compared with IL-1 $\beta$ alone or GlcN + IL-1 $\beta$ (Fig. $1 \mathrm{~A} ; \mathrm{P}<0.05$ ).

Next, the combined effect of Cit and GlcNAc on IL- $1 \beta$-stimulated IL- 6 production was evaluated. GlcNAc alone did not affect IL- 6 production by MH7A cells at $0.5 \mathrm{mM}$, whereas Cit significantly suppressed the IL-6 production $(\mathrm{P}<0.001)$, as described above. Notably, the combination of Cit and GlcNAc further reduced IL-6 production, compared with Cit alone, although the reduction was not significant. Furthermore, combination of Cit and GlcNAc significantly suppressed IL-6 production, compared with IL-1 $\beta$ alone and GlcNAc + IL-1 $\beta$ (Fig. 1B; P<0.001).

Subsequently, the combined effect of GlcN and GlcNAc on IL-1 $\beta$-stimulated IL- 6 production was evaluated. GlcN and GlcNAc alone did not significantly affect IL-6 production by MH7A cells. However, combination of GlcN and GlcNAc significantly suppressed IL-6 production, compared with IL-1 $\beta$ alone (Fig. $1 C ; \mathrm{P}<0.01$ ).

Morphological analysis of the cytotoxic effects of Cit, GlcN or GlcNAc on IL-1 $\beta$-stimulated human synovial MH7A cells was assessed. None of these substances induced cell death (such as apoptosis and necrosis) in IL-1 $\beta$-stimulated MH7A cells when incubated with 0.5 or $1.0 \mathrm{mM}$ of the compound (data not shown).

Effects of Cit, GlcNAc and GlcN on phosphorylation of $E R K 1 / 2$. It has been shown that GlcN exerts an anti-inflammatory effect by suppressing pro-inflammatory cytokine production at $>1 \mathrm{mM}$ on mouse macrophage-like cells (RAW 264.7), human umbilical vein endothelial cells (HUVECs) and human colonic epithelial cells (HT-29) due to the suppression of p38 MAPK and NF- $\kappa$ B signaling (18-20). Thus, to determine 

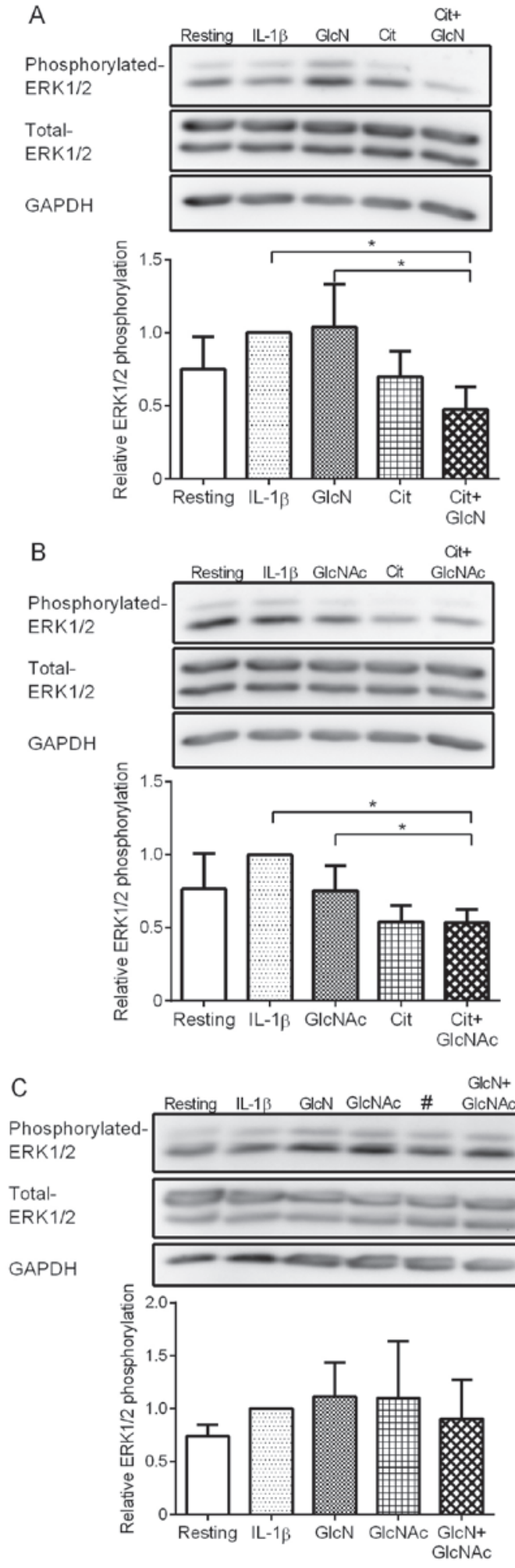

Figure 3. Effect of Cit, GlcNAc or GlcN, and their combinations on IL-1 $\beta$-stimulated phosphorylation of ERK1/2 by MH7A cells. (A) MH7A cells were incubated with or without IL- $1 \beta$ in the presence of $0.5 \mathrm{mM}$ GlcN, $0.5 \mathrm{mM}$ Cit or Cit $+\mathrm{GlcN}$ for $30 \mathrm{~min}$.(B) MH7A cells were incubated with or without IL-1 $\beta$ in the presence of $0.5 \mathrm{mM}$ GlcNAc, $0.5 \mathrm{mM}$ Cit or Cit + GlcNAc for 30 min. (C) MH7A cells were incubated with or without IL-1 $\beta$ in the presence of $0.5 \mathrm{mM}$ GlcN, $0.5 \mathrm{mN}$ GlcNAc, or GlcN + GlcNAc for $30 \mathrm{~min}$. Western blotting was performed to assess the expression of phosphorylated and total ERK1/2. GAPDH was used as the loading control. The blots are representative of three separate experiments. Data are presented as the mean \pm standard deviation of three separate experiments. " $\mathrm{P}<0.05$. \#, MH7A cells incubated with IL-1 $\beta$ and $0.5 \mathrm{mM}$ Cit, which was excluded from calculation of the data (graph) shown in (C) Cit, L-citrulline; GlcNAc, $\mathrm{N}$-acetylglucosamine; GlcN, glucosamine. whether the suppressive action of $\mathrm{Cit}+\mathrm{GlcN}$, Cit + GlcNAc, and GlcN + GlcNAc on IL-1 $\beta$-stimulated IL-6 production was also mediated by the suppression of p38 MAPK and NF- $\kappa B$ signaling, the effects of these substances on the phosphorylation of p38 MAPK and NF- $\mathrm{BB}$ p65 was investigated. IL-1 $\beta$ stimulation markedly increased the phosphorylation of p38 MAPK and NF-kB p65 (Fig. 2A and B). However, none of the treatments or their combinations $(0.5 \mathrm{mM}$ each) suppressed the $\mathrm{p} 38$ MAPK and NF- $\mathrm{KB}$ activation in synovial cells (Fig. 2A and B). It has also been shown that ERK1/2 signaling is involved in the IL-1 $\beta$-mediated activation of chondrocytes and osteoblasts (21). Thus, the combination of $\mathrm{Cit}+\mathrm{GlcN}, \mathrm{Cit}+\mathrm{GlcNAc}$, and GlcN + GlcNAc on suppression of IL-1 $\beta$-stimulated phosphorylation of ERK1/2 in synovial cells was determined. IL-1 $\beta$ stimulation only slightly but substantially increased the phosphorylation of ERK (Fig. 3). GlcN $(0.5 \mathrm{mM})$ alone did not affect the phosphorylation of ERK1/2 (Fig. 3A). Notably, Cit substantially suppressed the phosphorylation of ERK1/2, although the suppression was not statistically significant. Interestingly, the combination of Cit + GlcN further reduced the phosphorylation of ERK1/2, compared with Cit alone, although the reduction was not significant. Combination of Cit and GlcN significantly suppressed the phosphorylation of ERK1/2 compared with IL-1 $\beta$ alone and GlcN + IL-1 $\beta(\mathrm{P}<0.05)$.

The combined effect of Cit and GlcNAc on the IL-1 $\beta$-stimulated phosphorylation of ERK1/2 was evaluated. GlcNAc $(0.5 \mathrm{mM})$ alone did not notably affect the phosphorylation of ERK1/2 by MH7A cells (Fig. 3B), whereas Cit substantially suppressed the phosphorylation of ERK1/2 (Fig. 3A). Notably, the combination of Cit and GlcNAc suppressed the phosphorylation of ERK1/2 compared with IL-1 $\beta$ alone and GlcNAc + IL-1 $\beta(\mathrm{P}<0.05)$.

Finally, the combination of GlcN and GlcNAc on IL-1 $\beta$-stimulated phosphorylation of ERK1/2 was assessed. GlcN and GlcNAc alone did not significantly affect the phosphorylation of ERK1/2 in MH7A cells (Fig. 3C). However, the combination of GlcN and GlcNAc slightly suppressed the phosphorylation of ERK1/2 compared with GlcN and GlcNAc alone, although the suppression was not statistically significant.

\section{Discussion}

The aim of the present study was to evaluate the anti-inflammatory effects of Cit, GlcN and GlcNAc on synovial cells, and determine the combined effect of Cit, GlcN and GlcNAc on synovial cell inflammation, as assessed by the IL-1 $\beta$-induced IL-6 production. GlcN has been reported to significantly inhibit the production of inflammatory mediators and inflammatory cytokines such as $\mathrm{NO}, \mathrm{PGE}_{2}$ and IL-8 by synovial cells in vitro at a concentration of $1 \mathrm{mM}$ (9). Therefore, to evaluate the combined effects of Cit and GlcNAc with GlcN on IL- $1 \beta$-stimulated IL- 6 production by MH7A cells, the concentration of GlcN was reduced to $0.5 \mathrm{mM}$, a concentration at which GlcN did not significantly reduce IL-6 production (data not shown), and the concentrations of Cit and GlcNAc were also adjusted to $0.5 \mathrm{mM}$ (the same concentration as GlcN). The results showed that $0.5 \mathrm{mM}$ GlcN did not suppress IL-6 production (Fig. 1). Similarly, $0.5 \mathrm{mM} \mathrm{GlcNAc} \mathrm{did} \mathrm{not} \mathrm{suppress}$ IL-6 production, although $0.5 \mathrm{mM}$ Cit alone significantly 
suppressed IL- 6 production. The combined effect of Cit, GlcNAc and GlcN was examined, and the results showed that $\mathrm{Cit}+\mathrm{GlcN}$ and $\mathrm{Cit}+$ GlcNAc significantly suppressed not only IL-6 production but also the phosphorylation of ERK1/2. Combination of GlcN + GlcNAc also significantly suppressed IL-6 production and reduced phosphorylation of ERK1/2. These results suggest that among Cit, GlcNAc and $\mathrm{GlcN}$, combination of $\mathrm{Cit}+\mathrm{GlcN}$ and $\mathrm{Cit}+\mathrm{GlcNAc}$ more potently exerts an anti-inflammatory effect on synovial cells when combined, and may therefore possibly be used to alleviate inflammatory joint diseases. However, whether the combination of $\mathrm{Cit}+\mathrm{GlcN}$ and $\mathrm{Cit}+\mathrm{GlcNAc}$ exhibits anti-inflammatory and chondroprotective effects in vivo using animal OA models should be determined.

It has been shown that production of inflammatory cytokines and mediators following IL-1 $\beta$-stimulation is mediated by signaling pathways involving NF- $\mathrm{B}$, p38 MAPK, ERK1/2 and c-Jun N-terminal kinase (JNK) $1 / 2$ in chondrocytes (21). $\mathrm{GlcN}$ has been reported to exert its anti-inflammatory effects by inhibiting the production of inflammatory mediators and cytokines via suppression of the p38 MAPK and NF- $\kappa$ B signaling pathways in macrophages (murine macrophage cell line RAW264.7), endothelial cells (HUVECs) and colonic epithelial cells (human colon cancer cell line HT-29) (18-20). Furthermore, GlcN has been reported to suppress the IL-1 $\beta$-stimulated phosphorylation of p38 MAPK but not the phosphorylation of ERK1/2 and JNK1/2 in human chondrosarcoma cells (22), and GlcN suppressed IL-1 $\beta$-induced production of IL- 6 and cyclooxygenase- 2 expression in IL-1 $\beta$-stimulated chondrocytes without affecting ERK, JNK and p38MAPK signaling (14). Previously, the chondroprotective effect of $\mathrm{GlcN}$ was evaluated using chondrosarcoma SW1353 cells (22). In the present study, the protein expression of MMP-3 was significantly increased by IL-1 $\beta$ stimulation; however, the phosphorylation of ERK was only slightly increased by IL-1 $\beta$ stimulation. Thus, it is possible that the slight increase of phosphorylated ERK observed in the present study may also be involved in increased production of IL-6 following IL-1 $\beta$ stimulation.

Combination of $\mathrm{Cit}+\mathrm{GlcN}$ and $\mathrm{Cit}+\mathrm{GlcNAc}$ suppressed activity of the ERK1/2 signaling pathway, but not the p38 MAPK and NF- $\kappa \mathrm{B}$ signaling pathways. Thus, the combination of $\mathrm{Cit}+\mathrm{GlcN}$ and $\mathrm{Cit}+\mathrm{GlcNAc}$ may suppress the ERK1/2 signaling pathway, which is different from the pathway involved in GlcN or GlcNAc mediated suppression. Furthermore, the combination of $\mathrm{Cit}+\mathrm{GlcN}$ and $\mathrm{Cit}+\mathrm{GlcNAc}$ potently suppressed IL- $1 \beta$-stimulated IL- 6 production as well, compared with either GlcN or GlcNAc alone. Thus, it is likely that the combination of $\mathrm{Cit}+\mathrm{GlcN}$ and $\mathrm{Cit}+\mathrm{GlcNAc}$ synergistically exerts its anti-inflammatory action (suppression of ERK1/2 signaling and IL- 6 production) on synovial MH7A cells via different signaling pathway (ERK1/2) from those (p38 MAPK and NF- $\mathrm{BB}$ signaling pathways) involved in suppression mediated by GlcN or GlcNAc.

In conclusion, the combination of Cit with $\mathrm{GlcN}$ and GlcNAc synergistically exerted an anti-inflammatory effect on synovial cells, thereby possibly exhibiting chondroprotective effects and alleviating inflammatory joint disease. The enhanced effect of Cit was likely mediated via a different signaling pathway from those regulated by GlcN or GlcNAc.

\section{Acknowledgements}

The authors would like to thank Dr Taisuke Murakami and Dr Mamoru Igarashi (Department of Host Defense and Biochemical Research, Juntendo University, Graduate School of Medicine), for technical assistance and helpful discussions and Mr. Kiminori Iida (Protein Chemical Co., Ltd.) for supplying materials utilized in this study.

\section{Funding}

No funding was received.

\section{Availability of data and materials}

The datasets used and/or analyzed during the present study are available from the corresponding author on reasonable request.

\section{Authors' contributions}

YY and AS conceived and designed the study. YY and IN interpreted the results, and prepared the manuscript. All authors read and approved the final manuscript.

\section{Ethics approval and consent to participate}

Not applicable.

\section{Patient consent for publication}

Not applicable.

\section{Competing interests}

The authors declare that they have no competing interests.

\section{References}

1. Solomonson LP, Flam BR, Pendleton LC, Goodwin BL and Eichler DC: The caveolar nitric oxide synthase/arginine regeneration system for NO production in endothelial cells. J Exp Biol 206: 2083-2087, 2003.

2. Khalaf D, Krüger M, Wehland M, Infanger M and Grimm D: The effects of oral L-arginine and L-citrulline supplementation on blood pressure. Nutrients 11: E1679, 2019.

3. Breuillard C, Bonhomme S, Couderc R, Cynober L and De Bandt JP: In vitro anti-inflammatory effects of citrulline on peritoneal macrophages in Zucker diabetic fatty rats. Br J Nutr 113: 120-124, 2015.

4. Liu Y, Tian X, Gou L, Fu X, Li S, Lan N and Yin X: Protective effect of L-citrulline against ethanol-induced gastric ulcer in rats. Environ Toxicol Pharmacol 34: 280-287, 2012.

5. Darabi Z, Darand M, Yari Z, Hedayati M, Faghihi A, Agah S and Hekmatdoost A: Inflammatory markers response to citrulline supplementation in patients with non-alcoholic fatty liver disease: A randomized, double blind, placebo-controlled, clinical trial. BMC Res Notes 12: 89, 2019.

6. Jintake C, Azuma K and Okamoto Y: Combination of glucosamine hydrochloride and citrulline for experimental osteoarthritis model. Chitin Chitosan Res 25: 180, 2019 (In Japanese).

7. Largo R, Alvarez-Soria MA, Díez-Ortego I, Calvo E, Sánchez-Pernaute O, Egido J and Herrero-Beaumont G: Glucosamine inhibits IL-1beta-induced NFkappaB activation in human osteoarthritic chondrocytes. Osteoarthritis Cartilage 11: 290-298, 2003 
8. Naito K, Watari T, Furuhata A, Yomogida S, Sakamoto K, Kurosawa H, Kaneko K and Nagaoka I: Evaluation of the effect of glucosamine on an experimental rat osteoarthritis model. Life Sci 86: 538-543, 2010

9. Hua J, Sakamoto K, Kikukawa T, Abe C, Kurosawa H and Nagaoka I: Evaluation of the suppressive actions of glucosamine on the interleukin-1beta-mediated activation of synoviocytes. Inflamm Res 56: 432-438, 2007.

10. Nagaoka I: Recent aspects of the chondroprotective and anti-inflammatory actions of glucosamine, a functional food. Juntendo Med J 60: 580-587, 2014.

11. Ogata T, Ideno Y, Akai M, Seichi A, Hagino H, Iwaya T, Doi T, Yamada K, Chen ZA, Li Y and Hayashi K: Effects of glucosamine in patients with osteoarthritis of the knee: A systematic review and meta-analysis. Clin Rheumatol 37: 2479-2487, 2018.

12. Kubomura D, Ueno T, Yamada M and Nagaoka I: Evaluation of the chondroprotective action of N-acetylglucosamine in a rat experimental osteoarthritis model. Exp Ther Med 14: 3137-3144, 2017.

13. Shikhman AR, Brinson DC, ValbrachtJ and LotzMK: Differential metabolic effects of glucosamine and $\mathrm{N}$-acetylglucosamine in human articular chondrocytes. Osteoarthritis Cartilage 17: 1022-1028, 2009.

14. Shikhman AR, Kuhn K, Alaaeddine $\mathrm{N}$ and Lotz $\mathrm{M}$ : $\mathrm{N}$-acetylglucosamine prevents IL-1beta-mediated activation of human chondrocytes. J Immunol 166: 5155-5160, 2001.

15. Shikhman AR, Amiel D, D'Lima D, Hwang SB, Hu C, Xu A, Hashimoto S, Kobayashi K, Sasho T and Lotz MK: Chondroprotective activity of $\mathrm{N}$-acetylglucosamine in rabbits with experimental osteoarthritis. Ann Rheum Dis 64: 89-94, 2005.
16. Katsuno S, Eguchi C, Yoshimura K, Yamamoto T, Tomonaga A and Nagaoka I: Effects and safety of milk beverage contaning $\mathrm{N}$-acetyl glucosamine on knee joint pain and biomarkers of type II collagen metabolism: Preliminary study on open design. Jpn Pharmacol Ther 38: 435-445, 2010.

17. Naraoka Y, Harada H, Katagiri M, Yamamura H and Shirasawa T: $\mathrm{N}$-acetyl glucosamine and proteoglycan containing supplement improves the locomotor functions of subjects with knee pain. Drug Discov Ther 11: 140-145, 2017.

18. Rafi MM, Yadav PN and Rossi AO: Glucosamine inhibits LPS-induced COX-2 and iNOS expression in mouse macrophage cells (RAW 264.7) by inhibition of p38-MAP kinase and transcription factor NF-kappaB. Mol Nutr Food Res 51: 587-593, 2007.

19. Ju Y, Hua J, Sakamoto K, Ogawa $\mathrm{H}$ and Nagaoka I: Modulation of TNF-alpha-induced endothelial cell activation by glucosamine, a naturally occurring amino monosaccharide. Int J Mol Med 22: 809-815, 2008

20. Yomogida S, Hua J, Sakamoto K and Nagaoka I: Glucosamine suppresses interleukin- 8 production and ICAM-1 expression by TNF-alpha-stimulated human colonic epithelial HT-29 cells. Int J Mol Med 22: 205-211, 2008.

21. Jenei-Lanzl Z, Meurer A and Zaucke F: Interleukin-1 $\beta$ signaling in osteoarthritis-chondrocytes in focus. Cell Signal 53: 212-223, 2019.

22. Lin YC, Liang YC, Sheu MT, Lin YC, Hsieh MS, Chen TF and Chen $\mathrm{CH}$ : Chondroprotective effects of glucosamine involving the p38 MAPK and Akt signaling pathways. Rheumatol Int 28: 1009-1016, 2008. 